\title{
Czy powinniśmy zawsze ufać dokumentacji medycznej? Analiza przypadku chorej po implantacji kardiostymulatora z podejrzeniem jego dysfunkcji
}

\author{
Should we always trust medical records? Analysis of the case of a patient after \\ cardiac pacemaker implantation with suspected device dysfunction
}

\author{
Anna Kawińska-Hamala, Adam Pagórek, Jerzy Krzysztof Wranicz
}

Klinika Elektrokardiologii, Centralny Szpital Kliniczny w Łodzi, Uniwersytet Medyczny w Łodzi, Polska

\section{Streszczenie}

Rozwój techniki umożliwia konstruowanie i programowanie coraz bardziej zaawansowanych urządzeń stymulujących serce, co wiąże się również z rosnącymi wymaganiami wobec lekarzy, dotyczącymi wiedzy nt. rozruszników jak i interpretacji zapisu elektrokardiograficznego (EKG).Opis dotyczy 77-letniej pacjentki po implantacji kardiostymulatora (wg dostępnej dokumentacji - DDDR), z powodu choroby węzła zatokowego, przyjętej do oddziału, w związku z epizodem zasłabnięcia oraz uczuciem ogólnego osłabienia, w celu diagnostyki i kwalifikacji do dalszego leczenia. W EKG rejestrowano obraz bloku przedsionkowo-komorowego III stopnia (AVB III), bez danych na obecność stymulacji komorowej (nie obserwowano iglic komorowych). Postawione wstępne rozpoznanie kliniczne to dysfunkcja elektrody komorowej (przerwanie ciągłości elektrody, uszkodzenie portu), lub zaburzenia sterowania w kanale komorowym (oversensing w przebiegu szumów?, crosstalk?). EKG z magnesem pozwoliło wykluczyć zaburzenia o typie oversensingu. RTG klatki piersiowej i kontrola programatorem wykazały obecność u chorej kardiostymulatora jednojamowego-przedsionkowego (AAI). Ostatecznie implantowano chorej kardiostymulator dwujamowy (DDDR), doszczepiając elektrodę komorową i uzyskując ustąpienie dolegliwości pacjentki.

Słowa kluczowe: kardiostymulator, dysfunkcja elektrody, nadczułość

Folia Cardiologica 2018; 13, 4: 350-353

\section{Wstęp}

Historia implantowanych kardiostymulatorów sięga lat 50. XX w., kiedy wszczepiono pierwsze urządzenie [1]. Badania potwierdziły rosnące zastosowanie rozruszników serca we wszystkich grupach wiekowych, od noworodków, do osób w podeszłym wieku [2]. Układ stymulujący spełnia wiele funkcji, $m$. in. chroni przed nagłym zgonem sercowym spowodowanym przedłużającą się asystolią, zabezpiecza przed utratami przytomności spowodowanymi patologiczną bradykardią, synchronizuje pracę przedsionków i komór w przypadku bloku przedsionkowo-komorowego [3]. Rozwój techniki umożliwia konstruowanie i programowanie coraz bardziej zaawansowanych urządzeń, co wiąże się z rosnącymi wymaganiami wobec lekarzy, dotyczącymi wiedzy nt. kardiostymulatorów i interpretacji zapisu elektrokardiograficznego (EKG) [4].

\section{Opis przypadku}

Pacjentka 77-letnia po implantacji kardiostymulatora, z powodu choroby węzła zatokowego z poronnymi zespołami

Adres do korespondencji: Jerzy Krzysztof Wranicz, Klinika Elektrokardiologii, Centrum Kliniczno-Dydaktyczne, Centralny Szpital Kliniczny w Łodzi, Pomorska 251, 92-213 Łódź, Polska, e-mail: holter@csk.umed.lodz.pl 


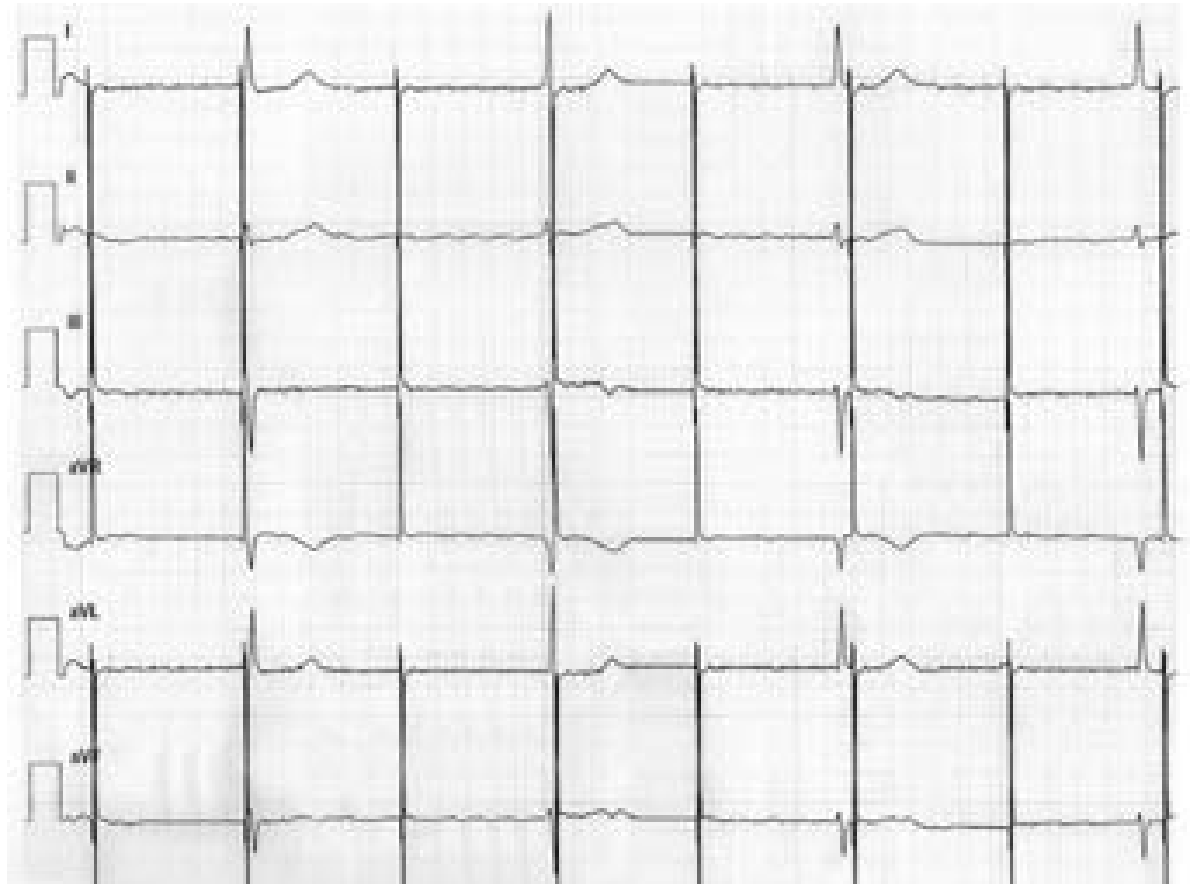

Rycina 1. EKG. Skuteczna stymulacja przedsionka z częstością 80/min, blok przedsionkowo-komorowy III stopnia z rytmem zastępczym ok. 40/min, oś pośrednia, QRS = 100 ms, bez przerostów komór, QT = 600 ms, odcinek ST w linii izoelektrycznej, bez cech przebytej martwicy i świeżego niedokrwienia

MAS (2007 r. - brak dokumentacji medycznej z okresu implantacji, w kartach wypisowych z innych hospitalizacji informacja o kardiostymulatorze w trybie DDDR), z chorobą wieńcową w I klasie wg CCS, nadciśnieniem tętniczym, cukrzyca t. II, przyjęta do oddziału, z powodu epizodu zasłabnięcia oraz ogólnego osłabienia, w celu diagnostyki i kwalifikacji do dalszego leczenia.

W badaniu przedmiotowym $\mathrm{HR}=40 / \mathrm{min}$., miarowa, RR 120/70 mm Hg, poza tym bez odchyleń od normy. Pierwszym, wykonanym w izbie przyjęć badaniem był 12-odprowadzeniowy EKG (ryc. 1, 2). Stwierdzono, że po każdej iglicy stymulacji przedsionkowej widać załamki p. Porównując rytm przedsionków (miarowy, 80/min) oraz komór (ok. 40/min) rozpoznano blok przedsionkowo-komorowy III stopnia (AVBIII). Z uwagi na opisywany tryb stymulacji DDDR 60/min, AVBIII oraz wolną czynność komór postawiono wstępną diagnozę zaburzeń pracy kardiostymulatora, dotyczących stymulacji/wyczuwania w kanale komorowym, prowadzących do całkowitego braku iglic w tym kanale. W wykonanym w izbie przyjęć EKG z magnesem nie uwidoczniono stymulacji komorowej, co pozwoliło wykluczyć zaburzenia o typie oversensingu.

Kontrola programatorem pozwoliła zidentyfikować kardiostymulator jako Biotronik Axios SR AAI. W RTG klatki piersiowej uwidoczniono implantowany układ jednojamowy - końcówka jedynej elektrody rzutowała się na prawy przedsionek.
Chorą zakwalifikowano do rozszerzenia układu do dwujamowego. Reimplantując urządzenie w trybie DDDR oraz doszczepiając elektrodę komorową, uzyskano całkowite ustąpienie dolegliwości.

\section{Dyskusja}

Lekarz izby przyjęć, kierując się informacjami zawartymi w dostępnej dokumentacji medycznej, traktował układ stymulujący serce jako układ dwujamowy. Z uwagi na całkowity brak iglic stymulacji komorowej uznał wstępnie, że problem w pracy kardiostymulatora może wynikać z zaburzeń wyczuwania o typie oversensingu (nadczułość) - używając słownictwa potocznego, kardiostymulator „nie widział” potrzeby stymulacji komory, ponieważ „widział” coś, co interpretował jako depolaryzacje komorową [5]. Biorąc pod uwagę różnego rodzaju zabezpieczenia stosowane przez producentów kardiostymulatorów, mające na celu ograniczenie występowania zjawiska oversensingu (noise revision circuit, bandpass filter, blanking period itp. [6]) oraz brak iglic stymulacji komorowej (utrzymujący się cały czas pomimo długiego okresu obserwacji chorej), nieprawidłowości w pracy kardiostymulatora o charakterze zaburzeń wyczuwania były mało prawdopodobne, ale niewątpliwie wymagały weryfikacji. Lekarz izby przyjęć, w celu potwierdzenia swojej wstępnej diagnozy, wykonał proste, ale jak najbardziej właściwe 


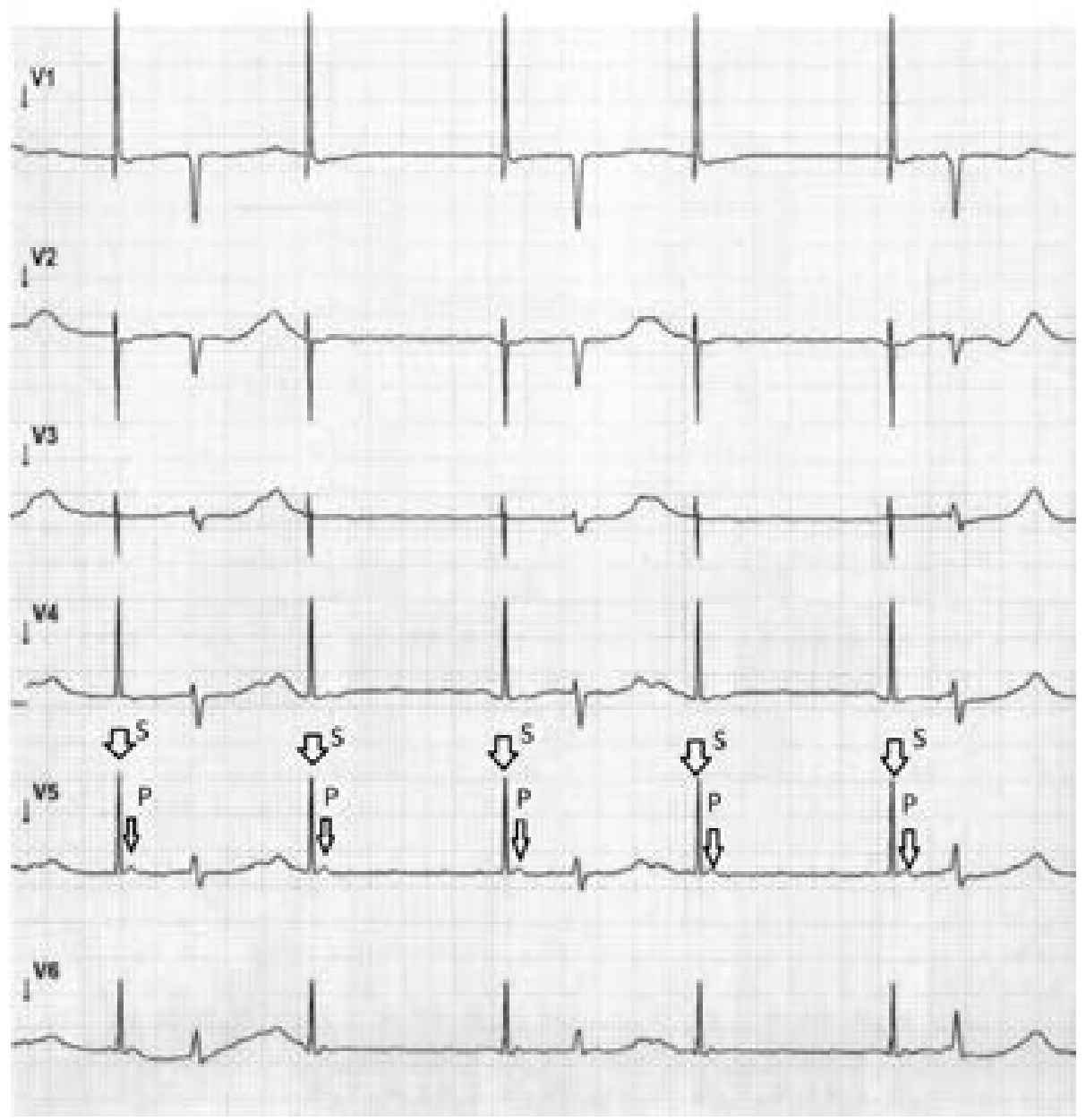

Rycina 2. EKG. Skuteczna stymulacja przedsionka z częstością 80/min, blok przedsionkowo-komorowy III stopnia z rytmem zastępczym ok. 40/min, oś pośrednia, QRS = 100 ms, bez przerostów komór, QT = 600 ms, odcinek ST w linii izoelektrycznej, bez cech przebytej martwicy i świeżego niedokrwienia

w opisywanej sytuacji badanie - EKG z magnesem. Pod wpływem pola magnetycznego dwujamowy kardiostymulator przechodzi w tryb pracy D00 [7], a więc wykonując to badanie „wyłącza się” wyczuwanie sygnałów elektrycznych. W przypadku istnienia przeszkody w pracy elektrody komorowej (w postaci sygnałów niewłaściwie odbieranych przez urządzenia, jako depolaryzacja komór) w EKG pojawiłyby się, nieobecne do tej pory, iglice stymulacji o zaprogramowanej przez producenta częstotliwości. Brak zapisu pracy elektrody komorowej w EKG po zastosowaniu magnesu spowodował, że lekarz izby przyjęć wykluczył oversensing i rozpoczął diagnostykę w kierunku zaburzeń stymulacji.

Najczęstsze przyczyny nieskutecznej stymulacji komorowej (takie jak np. dyslokacja elektrody) w EKG dają obraz iglic stymulacji, po których nie następują wystymulowane zespoły QRS. W opisywanym EKG zwraca uwagę całkowity brak iglic komorowych - tego typu zaburzenia stymulacji musiałyby mieć związek z całkowitym złamaniem elektrody komorowej, ewentualnie z uszkodzeniem portu lub niedokręceniem śrubki mocującej elektrodę w porcie kardiostymulatora (to jednak wykryte byłoby najprawdopodobniej we wczesnym okresie po implantacji układu). Ponieważ wydawało się, że ustalenie ostatecznej diagnozy wymaga wykonania kontroli parametrów kardiostymulatora lekarz izby przyjęć poprosił o konsultację kardiologiczną oraz przed przyjściem lekarza oddziału, wykonał zdjęcie rentgenowskie klatki piersiowej. Kontrola układu stymulującego dedykowanym programatorem pozwoliła na określenie takich parametrów jak m.in. próg stymulacji, oporność elektrod, stan napięcia ogniw baterii. Należy jednak zawsze pamiętać o prostym i ogólnie dostępnym badaniu jakim jest RTG klatki piersiowej, ponieważ uwidacznia ono układ (stymulator i elektrode (-dy) i jest bardzo pomocne w diagnozie takich nieprawidłowości jak przerwanie ciągłości lub dyslokacja elektrody. 


\section{Wnioski}

W przedstawionym przypadku, z uwagi na umieszczony w dokumentacji medycznej błędny wpis na temat trybu stymulacji, analiza EKG sugerowała zaburzenia o typie oversensingu lub uszkodzenie elektrody komorowej. Pomocne w weryfikacji rozpoznania były podstawowe badania, takie jak: EKG z magnesem i RTG klatki piersiowej, które choć nie zawsze dają ostateczną odpowiedź, mogą wykluczyć niektóre przyczyny (np. uszkodzenie ciągłości elektrody, oversensing) i pozwalają postawić wstępną diagnozę.

Drugim aspektem, jest zasada ograniczonego zaufania do dokumentacji medycznej. Na podstawie błędnej informacji z karty informacyjnej pobytu w szpitalu wysnuto niepoprawną koncepcję o dysfunkcji układu.

Warto wspomnieć, że według obecnie obowiązujących wytycznych ESC (European Society of Cardiology) układem pierwszego wyboru w objawowej bradykardii jest układ dwujamowy [8]. Jednakże, u opisywanej pacjentki kardiostymulator implantowano w 2007 r., według ówczesnych wytycznych ESC (w przypadku bradykardii bez bloku przedsionkowo-komorowego oraz częstoskurczu nadkomorowego preferowano tryb AAI) [9]. Wiedza o tym „starym” zaleceniu jest istotna obecnie, ponieważ może właśnie teraz nadszedł czas, w którym pacjenci po implantacji jednojamowego kardiostymulatora w przebiegu SSS będą ponownie szukali pomocy, z powodu nawrotu dolegliwości w przebiegu nowo powstałego AVB, przed którym wszczepiony stymulator nie może ich uchronić.

\section{Konflikt interesów}

Brak.

\section{Abstract}

Technological progress allows the construction and programming of more and more advanced heart-stimulating devices, which is also associated with the growing requirements for physicians' knowledge of pacemakers and the interpretation of electrocardiogram (ECG).

The paper presents a case of a 77-year-old female patient after cardiac pacemaker implantation (according to available documentation - DDDR), as a treatment of sinus node disease, admitted due to the episode of fainting and general weakness, for establishing diagnosis and qualification for further treatment. ECG revealed AV block III (AVB III), without ventricular pacing (absence of ventricular spikes). A preliminary clinical diagnosis was ventricular electrode dysfunction (interruption of the electrode continuity, damage to the port, loosening the screw), or disturbances in the ventricular channel (noise oversensing?, crosstalk?). ECG with a magnet allowed ruling out oversensitivity disorders. Chest x-ray and programmer control showed the presence of a single-chamber pacemaker - atrial (AAI) - in the patient. Finally, the patient was implanted with a dual-chamber pacemaker (DDDR) and additional ventricular electrode, which resulted in obtaining resolution of symptoms.

Key words: cardiac pacemaker, electrode dysfunction, oversensing

Folia Cardiologica 2018; 13, 4: 350-353

\section{Piśmiennictwo}

1. Kusumoto FM, Goldschlager N, Kusumoto FM, etal. Cardiac pacing. NEngl J Med. 1996; 334(2): 89-97, doi: 10.1056/NEJM199601113340206, indexed in Pubmed: 8531965.

2. Sridhar AR, Yarlagadda V, Yeruva MR, et al. Impact of haematoma after pacemaker and CRT device implantation on hospitalization costs, length of stay, and mortality: a population-based study. Europace. 2015; 17(10): 1548-1554, doi: 10.1093/europace/euv075, indexed in Pubmed: 25855676.

3. Walczak F, Baranowski R. Podstawy EKG u pacjenta ze stymulatorem serca. Wydawnictwo Medyczne Via Medica. Gdańsk; 2003: VII.

4. SERCA. Encyclopedic Dictionary of Genetics, Genomics and Proteomics. 2004, doi: 10.1002/0471684228.egp11418.
5. Dąbrowska B, Dąbrowski A. Podręcznik elektrokardiografii. Wydawnictwo Lekarskie PZWL. Warszawa.

6. Krupieniewicz A. Stymulacja serca. Wydawnictwo medyczne PZWL. Warszawa.

7. Kępski R. Stymulator serca. Wydawnictwo Lekarskie PZWL.: Warszawa.

8. Polska K. Wytyczne ESC dotyczące stymulacji serca i terapii resynchronizującej w 2013 roku. Kardiologia Polska. 2013; 71(V): 133-192, doi: 10.5603/kp.2013.0182.

9. Vardas PE, Auricchio A, Blanc JJ, et al. Wytyczne dotyczace stymulacji serca i resynchronizacji. Kardiologia Polska. 2007; 65: 12. 